\title{
O GRÊMIO DOS PROFESSORES PRIMÁRIOS DE PERNAMBUCO FABRICANDO BONS HÁBITOS: "A CAIXA ESCOLAR" (1883-1884)
}

\author{
PERNAMBUCO PRIMARY TEACHERS GUILD MAKING GOOD \\ HABITS: "A CAIXA ESCOLAR”(1883-1884)
}

\section{EL GREMIO DE MAESTROS PRIMARIOS DE PERNAMBUCO HACIENDO BUENOS HÁBITOS: “A CAIXA ESCOLAR” (1883- 1884)}

Dayana Raquel Pereira de Lima ${ }^{1}$

https://orcid.org/0000-0001-8985-494X

Adriana Maria Paulo da Silva ${ }^{2}$

https://orcid.org/0000-0002-7702-9501

\footnotetext{
${ }^{1}$ Universidade Federal de Pernambuco, Recife, Pernambuco - Brasil. E-mail: daylima27@gmail.com. ${ }^{2}$ Universidade Federal de Pernambuco, Recife, Pernambuco - Brasil. E-mail: adrianampsilva@gmail.com.
}

\section{Resumo}

Investigamos, com pesquisa documental direta e transcrição completa, 22 números -17 de 1883 e 5 de 1884 - do periódico quinzenal veiculado pela Associação do Grêmio dos Professores Primários de Pernambuco, sob a guarda do Arquivo Público Estadual Jordão Emerenciano (APEJE). Durante a análise dos assuntos debatidos e vivenciados pelos(as) docentes associados(as) localizamos a fundação, a organização e o funcionamento do dispositivo Caixa Escolar. Investigando os relatórios do Inspetor da Instrução Pública João Barbalho Uchôa Cavalcanti, identificamos que, na província de Pernambuco, o dispositivo Caixa Escolar foi propagandeado e instituído para a "moralização" financeira dos(as) alunos(as) das escolas primárias por meio da prática sistemática de poupança "benefício" para os(as) alunos(as) pobres (GRÊMIO, n 06, 1883; CAVALCANTI, 1878). Concluímos que esse instituto, nos embates emergidos da Associação do Grêmio dos Professores Primários, foi efetivado como uma importante estratégia (CERTEAU, 1998) para a "fabricação" de hábitos morigerados, de previdência e controle das crianças e jovens populares.

Palavras-chave: Grêmio dos Professores Primários. Instituto Caixa Escolar. Século XIX.

\section{Abstract}


We investigated, through direct documentary research and complete transcription, 22 issues - 17 issues from 1883 and 5 issues from 1884 - from the biweekly journal published by the Associação do Grêmio dos Professores Primários de Pernambuco, in the custody of the Arquivo Público Estadual Jordão Emerenciano (APEJE). During the analysis of the issues debated and experienced by the associate teachers, we located the foundation, organization and operation - of the Caixa Escolar device. Investigating the reports of the Inspector of Public Instruction João Barbalho Uchôa Cavalcanti, we found that in the Province of Pernambuco, the Caixa Escolar device was propagated and instituted for the financial "moralization" of primary school pupils through the systematic practice of "benefit" saving for the poor students (GREMMIO, no 06, 1883; CAVALCANTI, 1878). We conclude that this institute, in the emerged clashes of the Associação do Grêmio dos Professores Primários, was made effective as an important strategy (CERTEAU, 1998) for the "fabrication" of morigerated habits, welfare and control of popular children and youth.

Keywords: Primary Teachers Guild. Caixa Escolar Institute. XIX century.

\section{Resumen}

Buscamos, a través de la investigación documental directa y de la transcripción completa, 22 números - 17 de 1883 y 5 de 1884 - de la revista quincenal publicada por la Associação do Grêmio dos Professores Primários de Pernambuco, bajo la custodia del Arquivo Público Estadual Jordão Emerenciano (APEJE). Durante el análisis de los temas debatidos y experimentados por los profesores asociados, localizamos la fundación, la organización y el funcionamiento del dispositivo Caixa Escolar. Al investigar los informes del Inspector de Instrucción Pública João Barbalho Uchôa Cavalcanti, encontramos que, en la provincia de Pernambuco, el dispositivo Caixa Escolar se propagó e instituyó para la "moralización" financiera de los alumnos de primaria a través de práctica sistemática de ahorro de "beneficio" para los estudiantes pobres (GRÊEIO, no 06, 1883; CAVALCANTI, 1878). Llegamos a la conclusión de que este instituto, en los enfrentamientos surgidos de la Associação do Grêmio dos Professores Primários, se hizo efectivo como una estrategia importante (CERTEAU, 1998) para la "fabricación" de hábitos morigerados, la seguridad social y el control de niños y jóvenes populares.

Palabras clave: Gremio de Maestros de Primaria. Instituto Caixa Escolar. Siglo XIX.

\section{Introdução}

Consenso na historiografia da educação dos países ibéricos é o entendimento segundo o qual a escolarização pública sistemática, às expensas e sob o direcionamento do Estado, foi desenvolvida com muitas resistências por parte das suas elites desde o início e ao longo do século XIX (ALVAREZ-URIA e VARELA, 1991; FERNANDES, 1994).

No caso do mundo ibero-americano e, particularmente, do Império escravista do Brasil, essa afirmação também pode ser feita. 
Em Portugal, em fins do século XVIII e início do XIX, as ações educacionais objetivaram "a defesa dos valores ideológicos e dos interesses dominantes da sociedade do Antigo Regime". O efetivo sucesso das ações educacionais dependia da distribuição, pelos agentes públicos ou particulares, de uma instrução às crianças e aos jovens pobres que mantivessem as estratificações sociais (aceitas como naturais e fixas) mediante a formação moral - mecanismo de contenção dos "costumes depravados da pobreza" - e a preparação para o trabalho técnico (FERNANDES, 1994, p. 133).

No processo de formação do Estado Imperial, no Brasil, e de seus grupos dirigentes (ocorrido, justamente, na primeira metade do Oitocentos), o direcionamento das práticas, "instâncias e agentes públicos ou particulares de instrução/educação", objetivou garantir a unidade imperial e, ao mesmo tempo, "conseguir a adesão do "povo mais ou menos miúdo"” ao projeto imperial, com a intenção explícita de diminuir e direcionar “(...) a delinquência a eles associada" (SILVA, 2007, p. 229; MATTOS, 1990).

Na primeira metade do século XIX, no Brasil imperial, a educação primária como projeto do Estado em formação, sobretudo a partir da década de 1830, constituiu-se como um dos principais instrumentos para a manutenção das hierarquizações sociais (e políticas) herdadas desde o período colonial. Além dos critérios de liberdade (se livre ou escravo), de propriedade (se proprietário ou despossuído), o acesso à instrução que seria, em tese, um elemento socialmente equalizador das diferenças desses tipos, também foi política e socialmente utilizado como fator de hierarquização de pessoas e de lugares, conforme a sociabilidade excludente do Império escravista do Brasil.

Aprendemos há muito, com Ilmar Mattos, ter cabido à instrução pública e aos seus agentes a difusão dos valores e das aspirações das elites hegemônicas, tecedoras da política imperial e de si mesmas, enquanto classe senhorial (MATTOS, 1990). Nesse processo, vários projetos de instrução para o "povo" (escrito assim, com letras minúsculas) estiveram em disputa, ora enfatizando a necessidade de aproximação das práticas de escolarização com o mundo do trabalho, ora enfatizando unicamente seu caráter moralizador e/ou doutrinador (SILVA, 2000, p. 70-73). Durante a segunda metade do século XIX, apesar de vários aspectos da institucionalidade imperial terem se modificado, essa situação permaneceu e os diferentes projetos educacionais para formação dos indivíduos pobres e para o trabalho, entre as décadas de 1870 e 1880, permaneceram submetidos às ações do governo, muito embora iniciativas privadas, sociedades de professores e de outros trabalhadores também tenham entrado nessas 
disputas. Esses projetos enquadravam as camadas populares nos liames da instrução elementar, por intermédio das estratégias intelectuais e morais, adequadas ao exercício das profissões mercantis e artesanais (SCHUELER, 1997).

À vista do exposto analisaremos uma estratégia escolar de controle e moralização das crianças e jovens pobres no Recife do Oitocentos: a prática da "caixa escolar". E faremos isso por meio das publicações do periódico quinzenal intitulado Revista do Grêmio dos Professores Primários, sob a guarda do Arquivo Público Estadual Jordão Emerenciano (APEJE), produzidas entre os anos de 1883 e 1884 pelos membros da Sociedade do Grêmio dos Professores Primários, cuja fundação e regulamentação estatutária ocorreram em 25 de março de 1878.

Articularemos nossas leituras dos periódicos com a análise dos relatórios do Inspetor da Instrução Pública, João Barbalho Uchoa Cavalcanti, entre os anos de 1878 e 1885, especificamente, a respeito dos processos de fundação, organização e funcionamento das caixas escolares.

Pretendendo "combater o aniquilamento, melhorar e uniformizar a instrução pública" (PRIMÁRIOS, 1883, n. 1, p. 1), nos 22 números publicados (17 de 1883 e 5 de 1884), os periódicos do Grêmio apresentavam, em média, oito páginas divididas em seis seções.

Na seção intitulada "Matéria de capa", os(as) associados(as) divulgavam os assuntos mais urgentes e/ou polêmicos, envolvendo as condições de vida e trabalho docente: abertura e fechamento de escolas, pagamentos de salários e gratificações, críticas aos regulamentos vigentes da instrução pública, críticas ao quantitativo de verbas destinadas à instrução na época.

Na seção "Parte Noticiosa", seguiam os atos oficiais promovidos pela associação, como falas dos ocupantes de cargos superiores, divulgação de solenidades de outras sociedades pernambucanas (Sociedade Recreio Literário dos Normalistas e Sociedade Propagadora da Instrução Pública, por exemplo), bem como os balanços feitos pelas instâncias governamentais (Secretaria da Instrução Pública, Inspetoria da Instrução Pública e Presidência da Província) das expedições, aprovações e reprovações das petições dos expedientes práticos da docência e da instrução, como a criação e supressão de escolas públicas, nomeações ou exonerações dos delegados literários, aprovação de materiais didáticos, movimentação da Biblioteca do Grêmio, entre outros. 
$\mathrm{Na}$ "Parte Escolar", encontramos informações sobre o desenvolvimento das aulas relacionadas com diversas disciplinas (literatura, aritmética, álgebra, escrita etc.), divididas por dias da semana, turnos e classes, nas escolas públicas.

$\mathrm{Na}$ seção "Parte Literária", apareciam poesias escritas pelos(as) docentes sobre educação e instrução pública e notícias sobre falecimento de docentes ou seus familiares. E em "A quem interessar" anunciavam-se vendas de livros escritos pelos(as) docentes, considerados importantes para o uso nas escolas primárias urbanas e rurais, bem como as listas dos(as) associados(as), com os respectivos valores das anuidades. Por fim, havia a seção "Parte Pedagógica", na qual veiculavam-se os conhecimentos de higiene destinados aos alunos da Escola Normal e as orientações de organização e funcionamento das caixas econômicas escolares, seção na qual nos deteremos particularmente.

Do total de 869 docentes públicos primários de Pernambuco entre os anos de 1883 e $1884^{1}, 165$ (19\%) eram sócios(as) do Grêmio² ${ }^{2}$

Os debates veiculados nos periódicos do Grêmio tanto canalizaram as demandas e/ou críticas das condições de vida e trabalho dos(as) docentes públicos nele associados, indicaram aspectos das culturas escolares vivenciadas - disciplinas escolares, materiais para as escolas públicas secundárias e primárias da província - quanto foram importantes na veiculação estratégica de discursos direcionados à "fabricação" (também entre os docentes) de hábitos morigerados entre as crianças e jovens pobres, os quais frequentavam os espaços públicos de escolarização da cidade (CERTEAU, 1998).

\section{Instituto caixa escolar na segunda metade do século XIX}

[...] A escola é chamada efetivamente a exercer sobre a formação do caráter nacional um influxo benéfico, é do mais alto interesse que os poderes públicos a aproveitem, por ser o meio mais seguro de renovação das forças. Cumpre, não obstante, ponderar que tal influxo será menos o efeito da instrução que ela fornece, do que da parte que lhe deve caber na educação dos alunos que a frequentam. [...] Não é difícil imaginar quais consequências fecundas podem advir de uma escola onde os alunos entram com prazer, se retiram satisfeitos de si e dos exercícios cotidianos. O adiantamento

\footnotetext{
${ }^{1}$ Os quantitativos, especificamente por ano, correspondem a 475 docentes públicos(as) primários(as) em 1883 e 394 docentes em 1884 (CAVALCANTI,1883, p. 8; PERNAMBUCO, 1883, p. 33).

${ }^{2} \mathrm{O}$ quantitativo geral dos associados(as) foi obtido a partir do somatório dos nomes dos(as) docentes, contidos nas listas dos pagamentos da anuidade, nos 22 periódicos investigados (PRIMÁRIOS, $\mathrm{n}^{\circ} 1$ a 17, 1883; PRIMÁRIOS, nº 1, 5, 6, 10 e 15, 1884).
} 
mede-se ali pelos dias de aprendizado; as inteligências tardias com que se demandam, profundamente abaladas pelo estímulo, essa força elétrica que impulsiona o espírito da criança, e logra fazer da inveja uma virtude (PERNAMBUCO. Revista do Grêmio dos professores primário. Fala do Dr. A. H. de Souza Bandeira Filho na Parte Literária, nº 19, Ano II. Correio da Manhã: 1884, p. 6).

Na revista $O$ Grêmio dos Professores Primários, publicada em 1884, Dr. A. H. de Souza Bandeira Filho discutiu questões centrais sobre a influência preponderante da instrução pública no desenvolvimento social de sua época. Conforme o fragmento acima, a escola, descrita como o lugar de formação e renovação do caráter nacional, merecia maior atenção por parte dos "poderes públicos" menos pelo que poderia instruir e mais por seu potencial moralizador na vida dos alunos, estimulando-os a sentirem uma espécie de inveja "virtuosa" uns dos outros. Importantes estratégias de moralização difundidas pelos docentes associados foram as lições sobre economia pessoal aos alunos pobres, nas aulas públicas primárias pernambucanas, por meio da criação e do funcionamento da caixa econômica escolar.

Em Pernambuco, as caixas escolares, criadas na década de 1870, foram um desdobramento da Caixa Econômica Provincial ou de Socorro da Província, existente na localidade desde meados da década de 1840. Criada pelo presidente da província, Antonio Pinto Chicorro da Gama, pela Lei n. 196, de 1847, a Caixa Econômica Provincial foi composta por fundos ou capitais formados pela contribuição anual de 5\% deduzida dos ordenados, honorários e quaisquer outros vencimentos dos empregados provinciais e municipais de toda a província - jubilados e aposentados, estrangeiros engajados e os empregados de comissão -, os quais tornaram-se acionistas particulares.

Os investimentos e contribuições nas caixas econômicas podiam elevar em até $10 \%$ a quantia inicialmente depositada pelos participantes. ${ }^{3}$ Acumulado o montante de 20 contos de réis, iniciariam as operações das caixas: desconto de letras da Tesouraria Geral e Provincial, bilhetes de alfândega e de quaisquer outros títulos do governo geral ou provincial, pagáveis a prazos fixos; empréstimos de dinheiro sob penhores de ouro, prata, diamantes e joias; compra e venda de moedas de ouro e prata, segundo as oscilações do mercado, entre outras movimentações. O valor máximo de empréstimo era 4 contos de réis, e o mínimo, 10 mil réis. Naquela ocasião, a Lei n. 196, de 1847, instituía a não dissolução da caixa econômica, senão

\footnotetext{
${ }^{3}$ O Dr. José Osório de Cerqueira, antes de proferir a lição sobre as caixas econômicas escolares, publicada no periódico $\mathrm{n}^{\mathrm{o}}$ 6, de 1883, indicou que a Caixa Econômica Provincial funcionava no largo da Matriz do Corpo Santo, localizada no Bairro do Recife, atual bairro do Recife Antigo (PRIMÁRIOS, $\mathrm{n}^{\circ}$ 6, 1883, p. 7).
} 
ao fim de 40 anos, em virtude do aparato legal ou votação dos acionistas em assembleia geral (PERNAMBUCO, 1847, p. 19-26).

As movimentações financeiras ocorridas na Caixa Econômica Provincial, com suas particularidades, tornaram-se inspirações aos professores e professoras primárias, na ocasião de criação, instalação e funcionamento das caixas escolares, entre os(as) associados(as) do Grêmio dos Professora Primários de Pernambuco.

Criada com um duplo propósito de "moralizar" os estudantes, aperfeiçoando o caráter e bons sentimentos, e de incutir-lhes a valorização do trabalho, formando "futuros cidadãos" zelosos e poupadores, o instituto caixa econômica surgiu na França, em 1836.

Mediante aulas teórico-práticas de economia, os(as) docentes convidavam os alunos a pouparem e depositarem uma quantia facultativa semanal, posteriormente destinada à Caixa Econômica Geral. Essa prática, ensaiada em três ou quatro localidades na França (não tivemos acesso às localidades) instituiu-se na Bélgica em 1840, sendo, em meados da década de 1860 , disseminada em escala mundial, alcançando países como Itália (1873), Inglaterra (1874) e Brasil. Em Pernambuco, angariando apoios e proteção dos particulares e governo, o delegado literário da Madalena (subúrbio do Recife), Dr. José Osório de Cerqueira, em fevereiro de 1878, propôs a criação das caixas econômicas nas escolas daquela localidade, e essa prática disseminou-se pela província depois de agosto do citado ano (CAVALCANTI, 1878, p. 5051).

Nessa década, as chamadas "províncias do Norte" sofriam um intenso declínio no setor agroindustrial provocado, entre outros fatores, pela reorganização e dinamização da produção do açúcar da beterraba pelos mercados concorrentes (ingleses e franceses) a partir da abolição da escravidão e da introdução de novos padrões técnicos, promovendo uma desvalorização dos preços na pauta de exportação. Mesmo com as medidas de "modernização" no processo de produção açucareira, sobretudo na década de 1870, os produtos de exportação não alcançaram um preço compatível com o mercado internacional. Em Pernambuco, o quadro de declínio econômico deixou os proprietários rurais insatisfeitos, desencadeando empréstimos concedidos pelo Estado na forma de subsídios agrícolas (EISENBERG, 1977). A crise vivida na produção açucareira obrigou os endividados proprietários rurais a venderem seus escravos às “províncias do Sul” (MELLO, 1999).

Crescente urbanização, declínio da mão de obra escrava, discussão sobre a emancipação do ventre e aumento da população urbana caracterizaram a década de 1870 
como divisor de águas da história do país. As mudanças sociais desencadearam posicionamentos favoráveis às eleições diretas na pauta de reformas políticas consideradas necessárias à época. Ganhou força o discurso de restrição do eleitorado nas eleições primárias.

Alicerçadas nos intensos embates acerca da situação econômica imperial e local, as autoridades debatiam as reformas eleitorais nos anos finais do Império. Os grupos dirigentes e proprietários das províncias do Norte e do Sul passaram a defender um aumento da seletividade dos eleitores, restringindo o direito de voto àqueles com maior independência econômica, atestada por posses e com capacidade intelectual comprovada pelo domínio da leitura e escrita; e esta articulação propiciou a promulgação, em 1881, da Lei Saraiva (SOUZA, 2012).

Tal foi o contexto discursivo, político e econômico dentro do qual as caixas econômicas escolares foram criadas: crise nas atividades exportadoras locais, inchaço populacional da capital (e das freguesias centrais, certamente), redução de oportunidades de trabalho, aumento dos conflitos urbanos/criminalidade, propostas de restrição do número de votantes tendo em vista os temores das elites dirigentes e a reverberação desse quadro nas práticas de escolarização, as quais passaram a contar com um expediente disciplinador imediato para a moralização dos hábitos das crianças e, por seu intermédio, dos populares.

No dia 26 de agosto de 1878, na escola do professor Augusto Wanderley, localizada na Passagem da Madalena (subúrbio do Recife), foi fundada oficialmente uma caixa escolar. Essa prática repetiu-se com êxito na escola prática da Escola Normal $;^{4}$ na escola pública primária do professor Vicente de Moraes Mello, na escola do Monteiro (bairro localizado no subúrbio do Recife) da Sociedade Propagadora da Instrução Pública na Escola Politécnica (estabelecimento particular) na aula primária do Arsenal da Marinha, bem como ganhou adeptos entre vários professores públicos primários, os quais instalaram caixas escolares em suas aulas (CAVALCANTI, 1878, p. 50-51).

Conforme o Dr. José Osório relatou ao Inspetor da Instrução Pública João Barbalho Uchôa Cavalcanti, aprender economia não consistia em estimular operações usurárias na infância, mas em exercitar a previdência e a moralidade,

\footnotetext{
${ }^{4}$ A Escola Prática foi criada por meio do Regulamento da Escola Normal de 1868, em seu art. $6^{\circ}$. Anexa à Escola Normal, era um espaço no qual os alunos mestres eram obrigados a fazer os exercícios práticos (seus “estágios”) ao se matricularem no segundo ano do curso (VILLA-BELLA, 1868, p.1-2).
} 
ao aconselhar o menino a ser poupador, mostrar-lhe que todos os objetos que o cercam custam esforço e trabalho, que não se deve desperdiçar, mostrar-lhe que é ação péssima estragar a roupa, rasgar o livro, cortar a canivete o banco, etc, que o mau hábito de gastar sem precisão é uma imprevidência fatal a necessidades futuras, que é bonito e muito útil economizar hoje para que não falte amanhã. Isto é, ensinar a ser virtuoso, é educar a mocidade na grande ciência da vida, evitando que se aumente o número de perdulários, dos pródigos e dos indigentes (OSÓRIO apud CAVALCANTI, 1879, p. 64).

Em época de crise, imaginamos a crença das autoridades na utilização desse expediente para minimizar os efeitos negativos da escassez material crônica, a qual era submetida à escolarização pública em geral e, em particular, a parcelas significativas das famílias que a ela procuravam ter acesso. Ao mesmo tempo, em épocas de crise também era comum haver uma redução grave da já reduzida frequência escolar. Desde fins da década de 1830, foram comuns as reclamações das autoridades locais sobre a baixa frequência de estudantes nas aulas públicas primárias, atribuída à má formação moral e intelectual dos docentes, acusados de distanciarem as famílias e alunos das aulas, e/ou à incúria dos pais dos alunos. Esses argumentos permaneceram ativos ao longo de todo o século (SILVA, 2013). E, para fazer o enfrentamento desse problema, as caixas escolares também foram utilizadas.

Na segunda metade do século XIX, com o Regulamento da Instrução de 1855, o qual instituiu a obrigatoriedade do ensino, coube às autoridades a responsabilidade de obrigarem ou punirem os pais e/ou responsáveis que descuidassem da frequência escolar de seus filhos e/ou pupilos. E, apesar desse regramento, até o fim dos anos 70 do século XIX, quase nada havia se modificado e as escolas seguiam com baixos índices de frequência escolar (SILVA, 2013).

Para superar esse problema, o Inspetor João Barbalho Uchôa Cavalcanti, em Relatório de 1879, propôs o emprego das caixas escolares como um mecanismo de auxílio aos gastos públicos com roupas, livros, calçados e utensílios necessários à instrução de estudantes pobres e de aumento dos níveis de frequência dos alunos nas aulas públicas. Indicou, além disso, a possibilidade da intervenção dos pais (ou de pessoas de sua escolha) para a administração das caixas escolares (CAVALCANTI, p. 69, 1879). 


\section{Os usos estratégicos das caixas escolares}

Demonstraremos a organização e o funcionamento das caixas escolares por meio da lição proferida pelo Dr. José Osório de Cerqueira, publicada na "Parte Pedagógica" do número 6 da Revista do Grêmio dos Professores. Na sequência, analisaremos as primeiras movimentações financeiras das caixas escolares em duas aulas primárias, masculina e feminina, localizadas no bairro da Boa Vista (bairro central do Recife), descritas nos relatórios da Inspetoria Pública.

$\mathrm{Na}$ ocasião da instalação da Caixa Econômica Escolar na aula prática do sexo masculino, anexa à Escola Normal, em 10 de junho de 1883, foi publicada uma lição na revista do Grêmio, proferida pelo delegado literário Dr. José Osório Cerqueira, a respeito dos conceitos econômicos necessários à compreensão daquele dispositivo caixa escolar.

Entendida como "porto de salvação" dos adultos e crianças da província, as caixas escolares desdobraram-se das transações feitas nas Caixas Econômicas, casas legalmente autorizadas para receberem pequenas quantias em depósito (ou capital, conforme a lição), com o intuito de pouparem algum dinheiro. Os depósitos recolhidos a esses estabelecimentos eram aumentados com uma pequena quantia, chamada juros. Decorrido o fim do primeiro prazo, ou seja, do tempo do depósito, aplicava-se mais uma taxa de juros e, a cada seis meses, o ciclo recomeçava em benefício do depositante: as taxas de juros aplicadas ao valor inicialmente depositado aumentavam o montante do capital.

Articulando a lição proferida na revista com os detalhamentos sobre as caixas escolares presentes no relatório do Inspetor da Instrução Pública João Barbalho Uchôa Cavalcanti, em 1878, aproximamo-nos das estratégias de organização, controle e previdência delimitadas pelos poderes públicos e professores primários aos alunos e alunas pobres da província pernambucana.

Os depósitos nas caixas escolares eram facultativos, tendo em vista evitar desconfianças, por parte dos pais, de que os(as) docentes pretendiam enriquecer. $\mathrm{O}$ intuito era, após as lições de economia dadas, por espontânea vontade, recolher as pequenas quantias, as sobras, que os pais davam para as "gulodices" semanais dos(as) estudantes (PRIMÁRIOS, no 6, 1883, p. 06).

O sucesso do funcionamento das caixas escolares dependia do conhecimento da organização, do controle e das finalidades por parte dos(as) docentes por cujas mãos 
passavam os depósitos dos(as) estudantes antes de recolhidos à Caixa Econômica Geral. As pequenas quantias que cada estudante entregava eram registradas pelo(a) professor(a) numa caderneta específica para os depósitos (um tipo de "cadastro") com o nome do(a) depositante (tendo que apresentá-la a cada novo depósito) e seu respectivo número de conta bancária.

Em Pernambuco, os pequenos depósitos eram recebidos, geralmente, nas segundasfeiras. Nesse dia, ao abrir a escola, o(a) professor(a) anunciava o exercício de economia. Apresentava um livro numerado, intitulado "Registro da Caixa Econômica Escolar", contendo 12 colunas verticais, correspondentes aos 12 meses do ano, e 31 linhas horizontais, correspondentes ao dia de cada mês, tendo, em cada uma das páginas, o nome do aluno depositante (na parte superior da página) e folhas soltas (espécie de envelopes) com espaços para o preenchimento da quantia depositada pelo aluno e inserção do dinheiro. Esses procedimentos preveniam fraudes e serviam de provas de depósito tanto para os pais quanto para os(as) docentes. No verso de cada folha solta entregue aos estudantes, imprimia-se uma breve informação sobre moral e o sistema da caixa econômica escolar.

Com o passar do tempo de contribuição, atingido o montante mínimo autorizado pelas regulamentações das caixas escolares, 1 franco na Bélgica e na França e 1 mil réis no Brasil, ocorria a transferência da quantia, em nome, data de nascimento e conta do aluno, para a Caixa Econômica Geral, onde começariam a correr os juros, conforme regras de transações demonstradas pela lição do Dr. José Osório.

Os saques das quantias, parciais ou totais, eram feitos pelo pai ou qualquer outro representante legal do aluno com a assinatura daquele e do(a) docente. Apenas 1 mil réis, a cada vez, eram transferidos para a Caixa Geral Provincial, ficando nas escolas as sobras em dinheiro até o início de um outro ciclo de poupança. As cadernetas eram arquivadas na escola, sob a guarda dos(as) docentes, e entregues aos estudantes para mostrarem às famílias.

Em casos de inexistência das caixas escolares nas escolas rurais, os procedimentos de depósitos feitos pelos(as) estudantes realizavam-se nas cidades e vilas nas quais houvesse Caixa Econômicas Geral ou agências. Nas vilas sem caixas gerais ou agências, os depósitos eram intermediados pelos coletores das rendas públicas, os quais se responsabilizavam por transferir as quantias para os locais com caixas gerais ou agências (CAVALCANTI, 1878, p. 54-55; PRIMÁRIOS, $n^{\circ}$ 6, 1883, p. 06). As caixas escolares, portanto, foram dispositivos de controle e previdência dos(as) estudantes em Pernambuco por intermédio da fabricação de hábitos morigerados presentes nas práticas do cotidiano escolar. 
O relatório do Inspetor da Instrução Pública João Barbalho Uchôa Cavalcanti, em 1881, trouxe informações sobre os primeiros resultados de funcionamento e movimentação das caixas escolares desde a fundação, em agosto de 1878, até 31 de dezembro de 1880 . Publicando as informações remetidas pelo delegado literário e fundador das caixas escolares, o Dr. Joé Osório de Cerqueira, o inspetor, relatou que, apesar das dificuldades de efetivação de algumas das caixas escolares, o empreendimento estava em andamento e proporcionaria as vantagens prometidas, visto o zelo e a boa vontade dos(as) docentes nos processos de organização e funcionamento. Naquela ocasião, não havia reclamações dos professores quanto à organização e ao funcionamento das caixas, apenas algumas queixas referentes à demora com que, na Caixa Econômica Geral, se processava o recolhimento do dinheiro depositado pelos alunos. Elas, porém, não impediram o crescimento anual do quantitativo das caixas escolares, números de depósitos, quantidade de cadernetas e valor total arrecadado, conforme demonstrado a seguir no Quadro 1.

Quadro 1 - Movimento das caixas econômicas escolares desde sua fundação, em 1878, até dezembro de 1880

\begin{tabular}{|l|l|l|l|l|}
\hline Anos & $\begin{array}{l}\text { Caixas } \\
\text { escolares }\end{array}$ & $\begin{array}{l}\text { Alunos } \\
\text { depositantes }\end{array}$ & $\begin{array}{l}\text { Cadernetas na caixa } \\
\text { geral }\end{array}$ & $\begin{array}{l}\text { Quantia total } \\
\text { recolhida (em } \\
\text { mil réis) }\end{array}$ \\
\hline $\mathbf{1 8 7 8}$ & 5 & 245 & 0 & $778 \$ 890$ \\
\hline $\mathbf{1 8 7 9}$ & 14 & 568 & 537 & $2: 941 \$ 540$ \\
\hline $\mathbf{1 8 8 0}$ & 24 & 1.098 & 895 & $6: 435 \$ 400$ \\
\hline
\end{tabular}

Fonte: CAVALCANTI, J. B. U. Relatório apresentado ao Presidente da Província de Pernambuco. Recife: Typographia de Manoel Figueroa de Faria \& Filhos, 1881, p. 65

De maneira geral, em três anos de funcionamento, os quantitativos das caixas escolares e números de alunos depositantes quase quintuplicaram. Houve um grande aumento de alunos com cadernetas na Caixa Geral, chegando a $81 \%$ o total de alunos depositantes com cadernetas, bem como as quantias totais recolhidas, em mil réis, aumentaram seis vezes. Esses quantitativos indicam o sucesso inicial do empreendimento. 
Nas páginas posteriores do relatório do Inspetor da Instrução Pública João Barbalho Uchôa Cavalcanti, em 1881, encontramos a movimentação das duas primeiras caixas escolares em funcionamento na província pernambucana, nas escolas primárias masculina e feminina, ambas localizadas no bairro da Boa Vista (bairro central do Recife).

A escola masculina, sob a direção do professor Vicente de Moraes Mello, movimentou, em três anos de sua existência, o seguinte demonstrativo, apresentado no Quadro 2, por número de alunos e quantia depositada.

Quadro 2 - Movimentação da caixa econômica da escola primária do sexo masculino (18781880).

\begin{tabular}{|l|c|c|c|r|}
\hline Ano & $\begin{array}{c}\text { Alunos } \\
\text { depositantes }\end{array}$ & $\begin{array}{r}\text { Depósitos } \\
\text { sacados (no } \\
\text { de alunos) }\end{array}$ & $\begin{array}{r}\text { Depósitos } \\
\text { (em mil } \\
\text { réis) }\end{array}$ \\
\hline $\mathbf{1 8 7 8}$ & 98 & 4 & 254.70 \\
\hline $\mathbf{1 8 7 9}$ & 152 & 34 & 740.920 \\
\hline $\mathbf{1 8 8 0}$ & 199 & 36 & 743.040 \\
\hline & Totais & 449 & 74 & 1.738 .020 \\
\hline
\end{tabular}

Fonte: CAVAlCANTI, J. B.U. Relatório apresentado ao Presidente da Província de Pernambuco. Recife: Typographia de Manoel Figueroa de Faria \& Filhos, 1881, p. 65.

Observamos um aumento significativo no número de alunos depositantes - de 98, em 1878, para 199, em 1880 - em três anos de funcionamento. Dos 199 alunos depositantes, 136 eram detentores das cadernetas da Caixa Econômica Geral. Esse achado demonstra que, em média, $68 \%$ dos alunos depositantes transferiram ao menos uma quantia de mil réis para a Caixa Econômica Geral.

Em três anos de funcionamento, dos $68 \%$ de alunos com as cadernetas, apenas $16 \%$ (74 depósitos sacados) fizeram saques parciais ou totais. Era majoritário o número de estudantes poupadores, indicando o sucesso inicial das caixas escolares.

Para fins comparativos, os valores totais dos depósitos na escola do professor Vicente (1.738\$020 réis, em 1880) correspondiam a 27\% da quantia total recolhida (6:435\$400 réis, em 1880) pelas caixas econômicas escolares, apresentadas no Quadro 1. Dado significativo, 
se pensarmos o bem-sucedido trabalho de convencimento dos alunos e pais relativo à importância de "poupar" dinheiro.

A escola feminina, dirigida por D. Sophia Guilhermina de Mello, efetivou sua caixa escolar em 23 de fevereiro de 1880. Após um ano de funcionamento, obteve a seguinte movimentação: 107 alunas fizeram depósito, no valor de 729.840 mil réis, sendo 89 delas (83\% do total de depositantes) detentoras de cadernetas da Caixa Geral, na qual foi depositado o valor de 683 mil réis. Entre o número de alunas depositantes, apenas seis (em média, 6\% do total de depositantes) sacaram o valor parcial ou total, contabilizando um total sacado de 3.860 mil réis (CAVALCANTI, 1881, p. 66).

Os docentes Vicente de Moraes Mello e D. Sophia Guilhermina de Mello, provavelmente casados, foram exemplos comumente percebidos, a partir dos sobrenomes dos professores e professoras do século XIX, do exercício do magistério pelos membros da mesma família. Nos casos em questão, trata-se de dois importantes nomes do magistério público primário pernambucano.

Em sua trajetória profissional, Vicente de Moraes Mello apareceu nas fontes investigadas como sócio interno da Sociedade Propagadora da Instrução Pública, em 1874, professor da Escola Prática, anexa à Escola Normal Oficial, em 1878, primeiro presidente do Grêmio dos Professores Públicos Primários e membro da comissão de redação dos periódicos daquela sociedade, em 1883. Esse fato reforça a hipótese de haver articulações políticas entre os membros das referidas associações (PRIMÁRIOS, nº 1 e 3, p. 3 e 5, 1883; SANTOS, 2014, p. 54). Por sua vez, em 1883, D. Sophia Guilhermina de Mello apareceu como membro da comissão de Proteção do Grêmio dos Professores Primários, juntamente com outras professoras primárias (PRIMÁRIOS, nº 1, 1883, p. 5).

Investigações interessadas no rastreamento das famílias de professores e professoras, via sobrenomes, têm apontado como o prestígio no magistério do século XIX ultrapassava as fronteiras do mérito, situando-se a docência como uma "herança imaterial" de transmissão familiar do ofício (MUNHOZ \& VIDAL, 2015). O prestígio adquirido pelo professor Vicente, nos anos de exercício do magistério público e em suas alianças políticas como sócio de duas importantes associações pernambucanas, proporcionou-lhe angariar as benesses dos poderes públicos: a sua escola serviu como "laboratório-modelo" de instalação, funcionamento e propaganda da caixa escolar. Para a professora Sophia, a honra de ser casada com o dito professor, pois a docência feminina não estava fora do controle masculino e 
dependia, para ser exercida, da comprovação do estado civil (solteira, casada ou viúva) da professora. Ela, Sophia, permitiu que a sua escola servisse como modelo inicial e de sucesso das caixas escolares nas aulas femininas da província (SILVA, 2011).

Os dados citados demonstram o sucesso inicial de instalação e funcionamento das caixas escolares nas aulas primárias masculina e feminina entre os anos de 1878 e 1881 . Nos ditos anos, os propósitos das lições sobre economia, com intuito de incutir o gosto por poupar, atingiram seus objetivos mediante o crescente quantitativo de depósitos feitos nas caixas escolares e provincial e o reduzido percentual de saques.

Na segunda metade do século XIX, as lições sobre econômica básica, lecionadas nas escolas públicas primárias aos alunos pobres, somaram-se aos propósitos morais e econômicos dos dirigentes locais difundidos pelos(as) docentes associados(as) ao Grêmio dos Professores Primários frente às reestruturações econômica e política da província pernambucana.

\section{Considerações finais}

Criado na França em meados da década de 1830, o Instituto Caixa Escolar disseminou-se em escala mundial, chegando em Pernambuco/Brasil na década de 1870. Naquela ocasião, por intermédio das lições sobre economia, os(as) professores(as) públicos(as) desenvolveriam hábitos de previdência e controle financeiro nos estudantes.

Indicamos as práticas de instalação e funcionamento das caixas nas escolas públicas primárias, veiculadas pelas revistas do Grêmio dos Professores Primários, entre os anos de 1883 e 1884, e pelos relatórios do Inspetor da Instrução Pública João Barbalho Uchoa Cavalcanti, entre os anos de 1878 e 1881, e concluímos que a caixa escolar foi um importante dispositivo de fabricação de hábitos morigerados de controle e previdência de estudantes mediante a inserção de lições sobre economia nas escolas e dos rituais de poupança (depósitos e saques) feitos pelos professores, pais e alunos.

Apontamos o inicial sucesso do empreendimento ao verificarmos o aumento significativo de alunos e alunas depositantes, com cadernetas na Caixa Econômica Geral, isto é, aqueles(as) que atingiram a quantia mínima de mil réis, bem como o número reduzido de saques feitos, indicativo do cumprimento das finalidades das caixas escolares. 
Investigações a respeito desse dispositivo no Pernambuco do Oitocentos precisam ser aprofundadas e, estabelecendo uma ponte analítica entre o passado e o tempo presente (CARRETERO, 1996), percebermos que o instituto da caixa escolar, não obstante possa ter tido especificidades, permaneceu sendo um importante dispositivo de regramento incentivado, inclusive, pelo Ministério da Educação (MEC/Brasil) até grande parte do século XX (OLIVEIRA \& NETA, 2002).

\section{Referências}

ALVAREZ-URIA, F.; VARELA, J. Arqueologia de la Escuela. 1. ed. Madrid: La Piqueta, 1991. $304 \mathrm{p}$.

CARRETERO, M. Construir e ensinar as ciências sociais e a história. Porto Alegre: Artes Médicas, 1996. 138 p.

CAVALCANTI, J. B. U. Estudo sobre o sistema de ensino primário e organização pedagógica das escolas da Corte, Rio de Janeiro e Pernambuco. Recife: Typographia de Manoel Figueiroa de Faria \& Filhos, 1879.

CAVAlCANTI, J. B. U. Relatório apresentado ao Presidente da Província de Pernambuco. Recife: Typographia de Manoel Figueroa de Faria \& Filhos, 1878.

CAVAlCANTI, J. B. U. Relatório apresentado ao Presidente da Província de Pernambuco. Recife: Typographia de Manoel Figueroa de Faria \& Filhos, 1881.

CAVAlCANTI, J. B. U. Relatório apresentado ao Exmo. Sr. Presidente da Província em 31 de janeiro de 1883. Recife: Typographia de Manoel Figueroa de Faria \& Filhos, 1883.

DE CERTEAU, M. A invenção do cotidiano: artes de fazer. 3. ed. Petrópolis: Editora Vozes, 1998. $351 \mathrm{p}$.

EISENBERG, P. Modernização sem mudança: a indústria açucareira de Pernambuco (18401910). 1. ed. Campinas: Paz e Terra, 1977. 294 p.

FERNANDES, R. Os caminhos do ABC: sociedade portuguesa e ensino de primeiras letras. 1. ed. Portugal: Porto Editora, 1994. 734 p.

MATTOS, I. R. de. O tempo saquarema: a formação do estado imperial. 2. ed. São Paulo: Hucitec, 1990. 311 p.

MELLO, E. C. de. O norte agrário e o Império (1871-1889). 1. ed. São Paulo: Topbooks, 1999. $304 \mathrm{p}$.

MUNHOZ, F. G.; VIDAL, D. G. Experiência docente e transmissão familiar do magistério no Brasil. Revista Mexicana de Historia de la Educación, Ciudad de México, v. 3, n. 6, p. 125$157,2015$. 
OLIVEIRA, F. de F. A.; NETA, F. O. A Caixa Escolar no processo de descentralização da educação pública no Rio Grande do Norte. In: CONGRESSO BRASILEIRO DE HISTÓRIA DA EDUCAÇÃO, n. 2, 2002, Natal. Anais [...] Natal: Instituto Federal do Rio Grande do Norte, 2002, p. 1-10. Disponível em: http://www.sbhe.org.br/novo/congressos/cbhe2/pdfs/Tema3/0362.pdf. Acesso em: 20 ago. 2017.

PERNAMBUCO. Decreto Lei nº 196, de 1847. Cria a Caixa Econômica Provincial. Coleção de Leis, Decretos e Resoluções da Província de Pernambuco. Recife, v. 10, p. 19-23

PERNAMBUCO. Fala com que o Sr. presidente, Desembargador José Manoel de Freitas abriu a sessão da Assembleia Legislativa Provincial do dia 03 de março de 1884. Recife: Typographia de Manoel Figueroa de Faria \& Filhos, 1883, p. 33. Disponível em http://brazil.crl.edu/bsd/bsd/701/000033.html. Acesso em: 10 mar. 2017.

PRIMÁRIOS, Grêmio dos Professores. Revista da Sociedade do Grêmio dos Professores Primários, $\mathrm{n}^{\circ}$ 1, APEJE, Recife, p. 1-8, 1883.

PRIMÁRIOS, Grêmio dos Professores. Revista da Sociedade do Grêmio dos Professores Primários, nº 3, APEJE, Recife, p. 1-8, 1883.

PRIMÁRIOS, Grêmio dos Professores. Revista da Sociedade do Grêmio dos Professores Primários, $n^{\circ}$ 6, APEJE, Recife, p. 1-8, 1883.

PRIMÁRIOS, Grêmio dos Professores. Revista da Sociedade do Grêmio dos Professores Primários, $\mathrm{n}^{\circ}$ 19, APEJE, Recife, p. 1-8, 1884.

SANTOS, Y. S. A sociedade propaganda da instrução pública e suas ações de qualificação profissional em Recife (1872-1903). 2014. 138 f. Dissertação (Mestrado em Educação) - Universidade Federal de Pernambuco, Recife, 2014.

SCHUELER, A. F. M. de. Educar e Instruir: a instrução popular na Corte Imperial - 1870 a 1889. 1997. 240 f. Dissertação (Mestrado em História) - Universidade Federal Fluminense, Niterói, 1997.

SILVA, A. M. P. da. Aprender com perfeição e sem coação: uma escola para meninos pretos e pardos na Corte. 1. ed., Brasília: Plano, 2000. 163 p.

SILVA, A. M. P. Processos de construção das práticas de escolarização em Pernambuco, em fins do século XVIII e primeira metade do século XIX. 1. ed. Recife: Editora da UFPE, 2007. 398 p.

SILVA, A. M. P. da. Notas para o estudo da instituição da obrigatoriedade da educação primária na província de Pernambuco. In: VIDAL, D. G.; SÁ, E. F. de; SILVA, V. L. G. da (org.). Obrigatoriedade escolar no Brasil. Universidade Federal do Mato Grosso: EdUFMT, 2013, p. 209-226.

SOUZA, F. A. e. Direitos políticos em depuração: a Lei Saraiva e o eleitorado do Recife entre as décadas de 1870 e 1880. 2012. 234 f. Dissertação (Mestrado em História) Universidade Federal de Pernambuco, Recife, 2012. 
LIMA, D. de; SILVA, A. M. P. da

VILLA-BELlA, B. de. Regulamento da Escola Normal em 21 de julho de 1868. Recife: Typographia de Manoel Figueroa de Faria \& Filhos, 1868.

Enviado em: 11/09/2019

Aprovado em: 26/03/2021

Publicado em: 15/06/2021 